\title{
Synthesis of ZnS, CdS and Core-Shell Mixed CdS/ZnS, ZnS/CdS Nanocrystals in Tapioca Starch Matrix
}

\author{
Karen Khachatryan, Gohar Khachatryan, Maciej Fiedorowicz \\ Department of Chemistry and Physics, Agricultural University, Cracow, Poland \\ Email: rrchacza@cyf-kr.edu.pl
}

Received 22 September 2015; accepted 14 November 2015; published 20 November 2015

Copyright (C) 2015 by authors and Scientific Research Publishing Inc.

This work is licensed under the Creative Commons Attribution International License (CC BY). http://creativecommons.org/licenses/by/4.0/

(c) (i) Open Access

\begin{abstract}
Gel of tapioca starch (TS) is a suitable matrix for the formation of $\mathrm{ZnS}$, CdS and core-shell $\mathrm{ZnS} / \mathrm{CdS}$ as well as CdS/ZnS quantum dots (QDs). These QDs reside in the matrix as non-agglomerating 3 $10 \mathrm{~nm}$ nanocrystals. It is demonstrated that amylopectin is responsible for the QDs formation rather than amylose. Combination of $\mathrm{ZnS}$ with $\mathrm{CdS}$ in the core-shell QDs results in the increase in the intensity of emission without any shift of its wavelength.
\end{abstract}

\section{Keywords}

Bilayered Quantum Dots, Luminescent Biocomposites, Quantum Dots, Tapioca Starch

\section{Introduction}

Quantum dots (QDs) are colloidal semiconducting nanocrystals composed of an inorganic core surrounded by an organic outer layer of surfactant molecules (ligands) [1]. They develop emission when excited with a UV light. The wavelength of emission depends on the size of the nanoparticles [2] [3]. Their semiconducting properties originate from their excitons confined in all three spatial dimensions [4]. Especially, useful are the core-shell type nanoparticles composed of two kinds of semiconductors, e.g. CdS/ZnS [5], CdSe/ZnS [6] and CdSe/CdS [7]. In each pair of the sulphides/selenides, the first of them plays a role of the core while the second one forms a shell extending the gap of the emission of the core QDs. Such paired nanoparticles are high-efficiency photoluminescent (PL) materials [8]. Such property extends a wide range of applications of QDs as transistors, components of solar cells, light-emitting devices and diode lasers; they can also be used as agents for medical imaging [9]-[12], fluorescent labels [13]-[15], fluorescent probes [16]-[20], and immunosensors [21] [22]. 
Concentration of diluted suspensions of nanoparticles of several materials results in agglomeration leading to loss of advantages resulting from their nanodimensions. Therefore, QDs are frequently synthesized in the presence of organic molecules which prevent them from agglomeration and form a coating for the QDs. Application of QDs in biological studies succeeded due to their conjugation with proteins [23]-[27], peptides and amino acids [28] [29]. Also polysaccharides were applied for that purpose. The studies involved amino polysaccharides such as chitosan [30]-[35], cellulose, starch and other polysaccharides [36]-[43].

Polysaccharides offer some advantage as they provide drawing luminescent foils with embedded QDs. Properties of the foils depend on the polysaccharide applied. In case of starches, their pasting ability and rheological properties of resulting pastes are essential for the attributes of nanocrystals and the resulting foil composites. However, our former studies showed that the anionic/nonionic character of the polysaccharide matrix was also a factor. These observations prompted us to check how the generated QDs would behave in the tapioca starch matrix. Tapioca (cassava, manioq, yucca) starch (TS) is a common, non-ionic starch known for providing smooth uniform gels of much lower viscosity than many other natural starches [44].

In this paper an original, simple and cheap in situ synthesis of ZnS, CdS, ZnS-CdS and CdS-ZnS core-shell QDs in aqueous TS gel is presented. Biocomposites were characterized by using photoluminescence (PL), FTIR and UV/VIS spectrometric techniques and Transmission Electron Microscopy (TEM). Thermal properties (DSC, TG) of biocomposites were also measured. In order to check the impact of the QDs formation on the structure of polysaccharide chains, the absolute molecular weights $\left(\mathrm{M}_{\mathrm{W}}\right)$ were measured for two dominating fractions of TS prior and after generation QDs. They were determined with a size exclusion chromatography with dual detection (SEC-MALLS-RI).

\section{Materials and Methods}

\subsection{Generation of QDs}

Tapioca starch (TS)/ZnS, CdS nanocomposites were prepared from gelatinized TS and either zinc acetate (Aldrich, 99.99\%) or cadmium acetate (Aldrich, 99.99\%) and $\mathrm{Na}_{2} \mathrm{~S}$ (Aldrich, $\mathrm{Na}_{2} \mathrm{~S} \cdot 9 \mathrm{H}_{2} \mathrm{O} \geq 99.99 \%$ ). TS (1 g in 30 $\mathrm{mL}$ of deionized water) was heated with continuous stirring until it was completely gelatinized $\left(70^{\circ} \mathrm{C}\right.$ for 30 $\mathrm{min}$ ), treated with $0.35 \mathrm{mmol}$ given salt solution (zinc or cadmium acetate), then a stoichiometric amount of 0.1 $\mathrm{M}$ aq. $\mathrm{Na}_{2} \mathrm{~S} \cdot 9 \mathrm{H}_{2} \mathrm{O}$ solution was added. To obtain nanocomposites with equal amounts of QDs, ZnS and CdS nanocrystals were prepared the same way as above but using half of substrates $(0.175 \mathrm{mmol}$ acetate solution and stoichiometric amount of $0.1 \mathrm{M}$ aq. $\mathrm{Na}_{2} \mathrm{~S} \cdot 9 \mathrm{H}_{2} \mathrm{O}$ solution). Core-shell $\mathrm{ZnS} / \mathrm{CdS}$ and $\mathrm{CdS} / \mathrm{ZnS}$ nanocrystals were generated by adding $0.175 \mathrm{mmol}$ acetate of a proper metal (Cd or $\mathrm{Zn}$ ) to either $\mathrm{ZnS}$ or CdS QDs followed by addition of a stoichiometric amount of $0.1 \mathrm{M}$ aq. $\mathrm{Na}_{2} \mathrm{~S} \cdot 9 \mathrm{H}_{2} \mathrm{O}$ solution.

All resulting suspensions were brought to room temperature then centrifuged. The deposits were applied to clean, smooth either Teflon or glass surfaces, and left for evaporation in the air. The dry foils were collected and stored in closed vessels.

\subsection{Transmission Electron Microscopy (TEM)}

Analyses of sizes and morphologies of the as-prepared nanoparticles were studied using a high resolution JEOL 7550 scanning electron microscope equipped with Energy dispersion X-ray spectroscopy (EDS) analyzer for local chemical analysis. Samples for TEM and SEM microscopies were prepared after drop-coating $10 \mu \mathrm{L}$ of the sample on a carbon-coated copper grid $\left(\right.$ PELCO $\left.^{\circledR}\right)$. Because the material was sufficiently conducting, the gold sputtering of the samples was dispensable.

\subsection{Size Exclusion Chromatography}

Molecular weight, $M_{w}$, and radii of gyration, $R_{G}$, of the polysaccharide chains from the nanocomposites samples were estimated with the system consisting of a pump (Shimadzu 10AC, Tokyo, Japan), an injection valve (model 7021, Rheodyne, Palo Alto, CA, USA), two connected size exclusion columns TSKgel GMPWXL (300 × 7.8 mm, Tosoh Corporation, Tokyo, Japan) and TSKgel 2500 PWXL $(300 \times 7.8$ mm, Tosoh Corporation, Tokyo, Japan), a multiangle laser light scattering detector (MALLS) (Dawn-DSP-F, Wyatt Technology, Santa Barbara, CA, USA) and a differential refractive index detector (L-7490, Merck, Darmstadt, Germany). 


\subsection{UV-VIS Spectroscopy}

The UV-VIS absorption spectra were recorded with a Shimadzu 2101 scanning spectrophotometer in the range of $200-800 \mathrm{~nm}$ using $10 \mathrm{~mL}, 10 \mathrm{~cm}$ thick quartz cells. Concentration of the solutions was $0.003 \mathrm{~g} / \mathrm{L}$.

\subsection{Photoluminescent Spectroscopy}

Photoluminescence (PL) measurements for films were performed at room temperature using F7000 HITACHI spectrophotometer. The $360 \mathrm{~nm}$ wavelength was used for the excitation.

\subsection{Thermogravimetry (TG)}

Thermogravimetric analysis coupled with mass spectrometry analyses (MS-TG/DTG/SDTA) was performed with a Mettler-Toledo 851e apparatus in $150 \mu \mathrm{l}$ corundum crucibles, closed by a lid with a hole. The experiments were run in the air $(80 \mathrm{~mL} / \mathrm{min})$ within the temperature range of and $30^{\circ} \mathrm{C}-700^{\circ} \mathrm{C}$ (the heating rate was $\left.10^{\circ} \mathrm{C} / \mathrm{min}\right)$.

\subsection{FTIR Spectroscopy}

The FTIR-ATR spectra of the film were recorded in the range of $4000-700 \mathrm{~cm}^{-1}$ at resolution of $4 \mathrm{~cm}^{-1}$ using a Mattson 3000 FT-IR (Madison, Wisconsin, USA) spectrophotometer. That instrument was equipped with a 30SPEC $30^{\circ}$ reflectance adapter fitted with the MIRacle ATR accessory from PIKE Technologies Inc., Madison, Wisconsin, USA.

\subsection{Differential Scanning Calorimetry (DSC)}

The differential scanning calorimetry (DSC) was performed in a Mettler-Toledo 821e calorimeter equipped with anHaakeintracooler in $40 \mu \mathrm{L}$ aluminum crucibles at a constant flow of argon $(80 \mathrm{~mL} / \mathrm{min})$ within temperature range of $25^{\circ} \mathrm{C}-500^{\circ} \mathrm{C}$.

\section{Results and Discussion}

The TEM microscopy showed metal sulfides under study embedded in the TS matrix as 3 - $10 \mathrm{~nm}$ nanocrystals with a low tendency for agglomeration (Figure 1). This result confirmed our observation that nonanionic polysaccharides were superior matrices for generation of nanocrystals of metallic [45] and QDs [42] [43] particles.

The matrices made of anionic starches favored formation of much larger and agglomerating nanocrystals (Khachatryan, K., Khachatryan, G., Fiedorowicz, M., Distarch phosphate as a matrix for generation of quantum dots, Iran. J. Chem. Chem. Eng., submitted, 2015).

TS was separated with size exclusion chromatography into fractions among which two fractions dominated. They were higher molecular fraction of $\mathrm{M}_{\mathrm{w}}=1.18 \times 10^{6} \mathrm{~g} / \mathrm{mol}$ and lower molecular fraction of $\mathrm{M}_{\mathrm{w}}=1.27 \times 10^{5}$ $\mathrm{g} / \mathrm{mol}$. The amount ratio of the collected fractions was high: low $=1.82$. After generation of $\mathrm{ZnS}$ and $\mathrm{ZnS} / \mathrm{CdS}$ QDs also two dominating fractions could be distinguished in the eluates but in the proportions of high: low = 0.43 and 0.47 , respectively. Size exclusion chromatography of TS after generation CdS and CdS/ZnS QDs provided in the first case two fractions in that proportion of 0.69 and in the second case only low molecular fraction could be collected from the column. $\mathrm{M}_{\mathrm{w}}$ of all collected fractions insignificantly differed from the corresponding values for original gelatinized TS.

Thus, one could deduce that the generation of QDs within the high molecular weight fraction of the gel was favored. That observation fitted results of the study by Ciesielski and Tomasik [45] that amylopectin formed Werner complexes with metal ions whereas amylose was passive as a ligand.

The UV-VIS spectrum of TS (Figure 2) demonstrated a low absorption shoulder around $250 \mathrm{~nm}$ belonging likely to $\mathrm{n} \rightarrow \pi^{*}$ transitions in the lone electron pairs at the oxygen atoms. All preparations of TS with embedded QDs showed a strong absorption band around $220 \mathrm{~nm}$ followed by the long wavelength tail reaching its bottom in the spectrum of TS/ZnS already around $330 \mathrm{~nm}$ and between $450-500 \mathrm{~nm}$ in the spectra of the preparations containing CdS (Figure 2).

The emission spectra of the preparations (Figure 3) showed an emission maximum from TS/ZnS and TS/CdS around 440 and $540 \mathrm{~nm}$, respectively. Supplementation of ZnS within TS with CdS QDs appeared very successful 

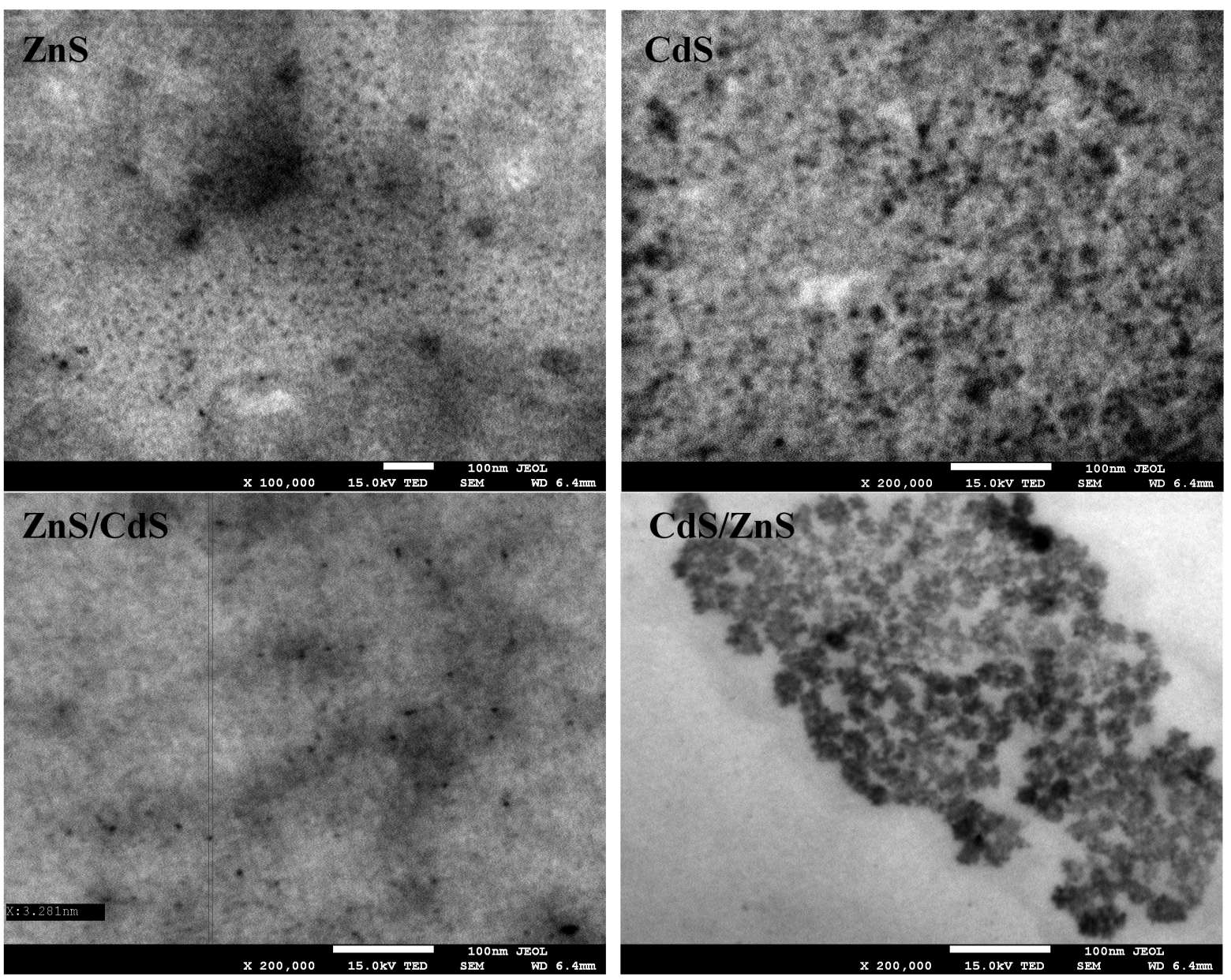

Figure 1. Taken at 100000 (ZnS) and 200,000 (CdS, ZnS/CdS and CdS/ZnS) magnification TEM micrographs of QDs embedded in the TS matrix.

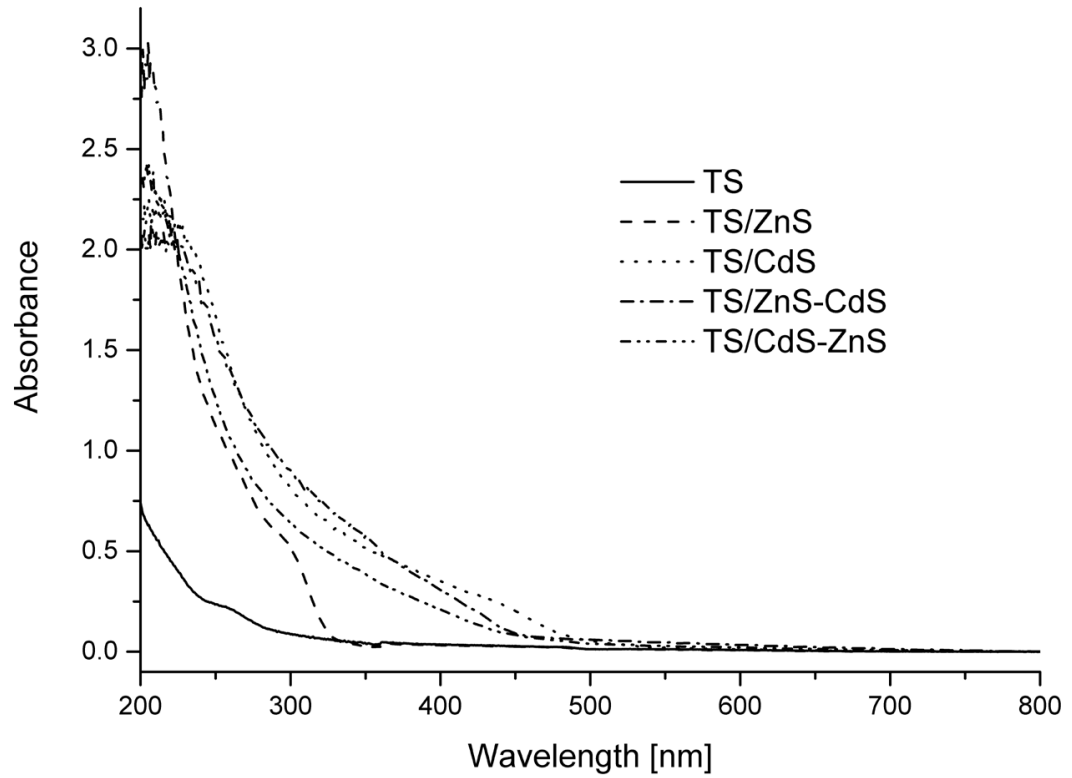

Figure 2. UV-VIS spectra of TS and QDs embedded in the TS matrix. 


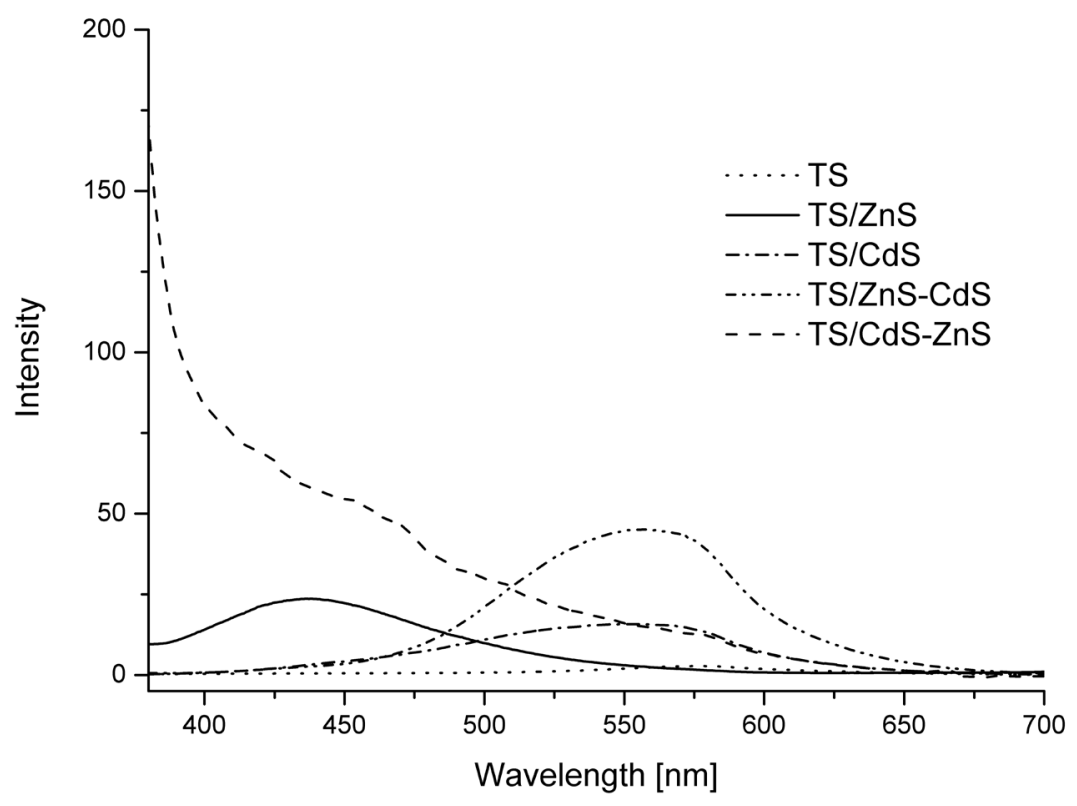

Figure 3. PL spectra of TS and QDs embedded in the TS matrix.

in a significant raising the intensity of the emission maximum, however, without a shift of the wavelength of the emission. The increase in the intensity of the emission band could be observed when in the TS/CdS preparation ZnS was additionally generated. The shoulder of an intensive emission could be observed around $440 \mathrm{~nm}$ (Figure 3). These effects showed that blending QDs of two different origins was a very successful approach in increasing the intensity of emission. The emission patterns implied that the original QDs were the nuclei for the formation of the subsequent QDs, thus the binary QDs could be bilayered species.

Thermograms of TS (Figure 4) showed that the polysaccharide lost $\sim 10 \%$ of its weight around $100^{\circ} \mathrm{C}$. That loss resulted from departure of the absorbed moisture. That effect was followed by a rapid loss of further 16\% weight at approximately $250^{\circ} \mathrm{C}$. It could be associated with a departure of water molecules on formation of 3,6-anhydro derivatives of TS. Subsequently, TS lost further $\sim 45 \%$ weight to $320^{\circ} \mathrm{C}$ and another $\sim 25 \%$ up to $450^{\circ} \mathrm{C}$. Above $450^{\circ}$ there was no further decomposition and the weight stabilized on the level of $5 \%$ residual carbonizate.

The decomposition pattern of the TS/QDs preparations was initially similar. The preparations lost some moisture then began to decompose at the same temperature as plain TS. Further decomposition pattern was different. The preparations lost their weight less rapidly and only TS/CdS decomposed up to $320^{\circ} \mathrm{C}$ in two well distinguished steps. Some slight increase in the weight after initial decomposition could result from a reaction of CdS with atmospheric oxygen as such effect was absent when thermogravimetry was run under argon. Further decomposition pattern for all other preparations was the same. Temperatures of the corresponding decomposition steps were the same and only the weight of the residues was different. The latter were approximately $15 \%$, $12 \%, 8 \%$ and $8 \%$ for TS with embedded ZnS, CdS, ZnS-CdS and CdS-ZnS, respectively.

Such course of decomposition might suggest that the introduction of QDs into the TS gel could influence the internal structure of the gel but they did not form complexes with the polysaccharide. The latter assumption was backed by analysis of FTIR spectra of particular preparations and differential scanning calorimetry (DSC). All FTIR spectra were identical (Figure 5).

The DSC diagrams of TS and TS/QDS preparations differed solely in the low temperature region where endothermic effects associated with physical water-polysaccharide relations appeared. Further parts of the diagrams showed a close resemblance (Figure 6). There were slightly exothermic effects around $250^{\circ} \mathrm{C}$ common for all samples. The major exothermic effect of comparable magnitude occurred around $320^{\circ} \mathrm{C}$.

\section{Conclusions}

1) Tapioca starch is suitable as the matrix for QDs as it limits the growth of QDs particles and prevents them 


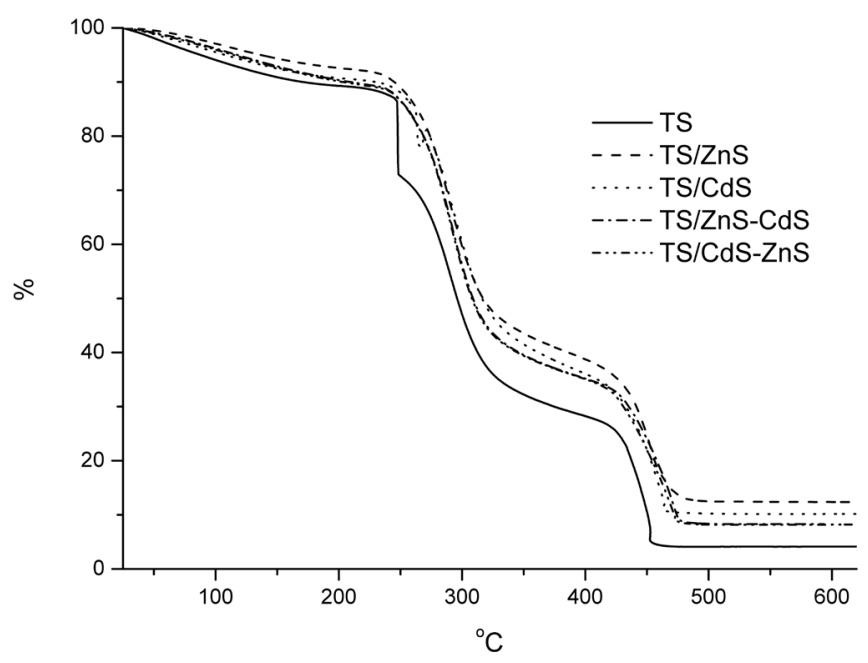

Figure 4. Thermograms of TS and TS/QDs preparations taken in the air.

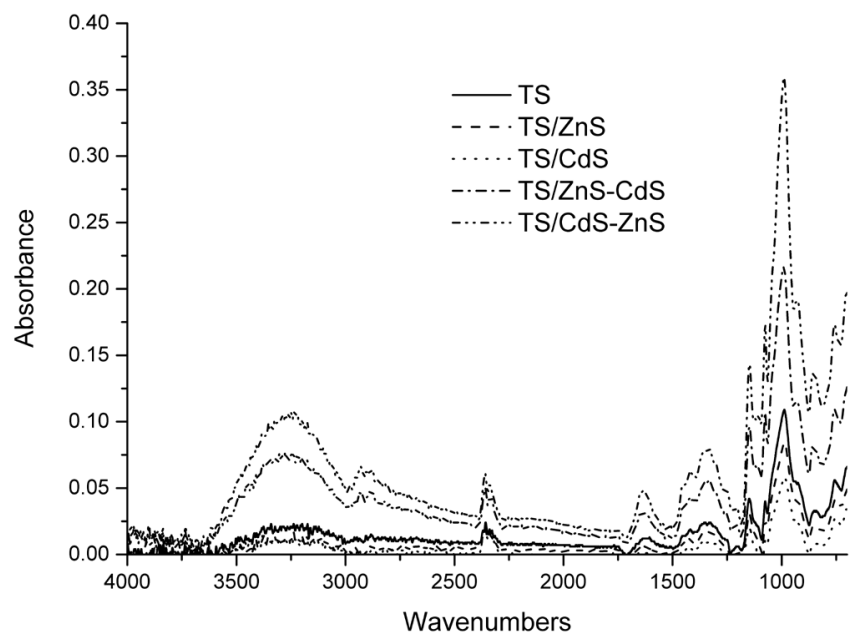

Figure 5. FTIR-ATR spectra of TS and TS/QDs foils.

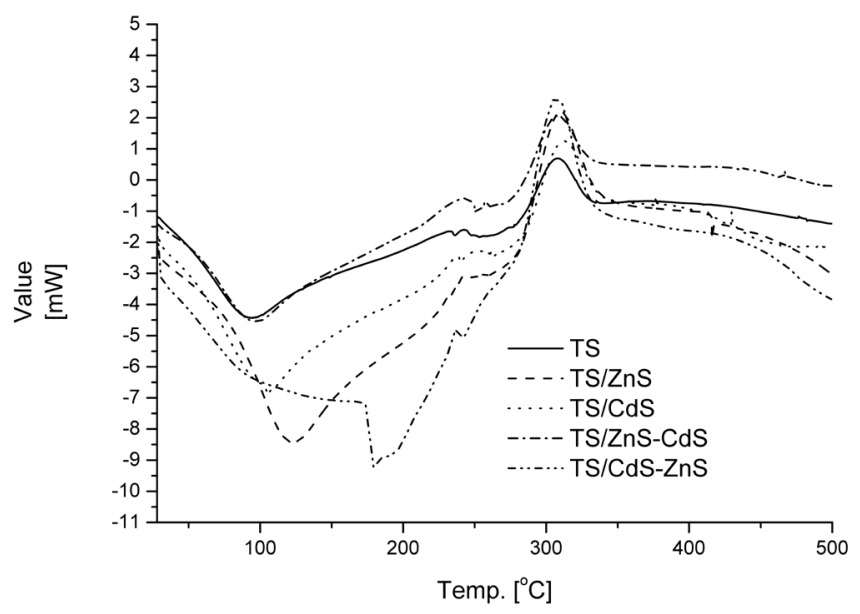

Figure 6. DSC diagrams of TS and its preparations containing QDs. 
from agglomeration.

2) The core-shell technique of the generation of binary QDs provides a significant increase in the emission intensity without any shift of the emission wavelength. The recorded emission comes from the shell forming component.

\section{References}

[1] Reiss, P., Protière, M. and Li, L. (2009) Core/Shell Semiconductor Nanocrystals. Small, 5, 154-168. http://dx.doi.org/10.1002/smll.200800841

[2] van Driel, A.F., Allan, G., Delerue, C., Lodahl, P., Vos, W.L. and Vanmaekelbergh, D. (2005) Frequency-Dependent Spontaneous Emission Rate from CdSe and CdTe Nanocrystals: Influence of Dark States. Physical Review Letters, 95, 236804-236808. http://dx.doi.org/10.1103/PhysRevLett.95.236804

[3] Wang, Y.X., Fan, H.G., Wang, D.D. and Lang, J.H. (2008) Low Temperature Synthesis and Characterization of ZnO Quantum Dots. Journal of Alloys and Compounds, 463, 92-95. http://dx.doi.org/10.1016/j.jallcom.2007.12.006

[4] Murray, C.B., Kagan, C.R. and Bawendi, M.G. (2000) Syntesis and Characterization of Monodisperse Nanocrystals and Close-Packed Nanocrystal Assemblies. Annual Review of Materials Science, 30, 545-610. http://dx.doi.org/10.1146/annurev.matsci.30.1.545

[5] Qi, L., Ma, J., Cheng, H. and Zhao, Z. (1996) Synthesis and Characterization of Mixed CdS/ZnS Nanoparticles in Reverse Micelles. Colloids and Surfaces A: Physicochemical and Engineering Aspects, 111, 195-202. http://dx.doi.org/10.1016/0927-7757(96)03545-5

[6] Dabbousi, B.O., Rodriguez-Viejo, J., Mikulec, F.V., Heine, J.R., Mattoussi, H., Ober, R., Jensen, K.F. and Bawendi, M.G. (1997) (CdSe)ZnS Core-Shell Quantum Dots: Synthesis and Characterization of a Size Series of Highly Luminescent Nanocrystallites. The Journal of Physical Chemistry B, 101, 9463-9475. http://dx.doi.org/10.1021/jp971091y

[7] Peng, X., Schlamp, M.C., Kadavanich, A.V. and Alivisatos, A.P. (1997) Epitaxial Growth of Highly Luminescent CdSe/CdS Core/Shell Nanocrystals with Photostability and Electronic Accessibility. Journal of the American Chemical Society, 119, 7019-7029. http://dx.doi.org/10.1021/ja970754m

[8] Loukanov, A.R., Dushkin, C.D., Papazova, K.I., Kirov, A.V., Abrashev, M.V. and Adachi, E. (2004) Photoluminescence Depending on the ZnS Shell Thickness of CdS/ZnS Core-Shell Semiconductor Nanoparticles. Colloids and Surfaces A: Physicochemical and Engineering Aspects, 245, 9-14. http://dx.doi.org/10.1016/j.colsurfa.2004.06.016

[9] Itoh, J. and Osamura, R.Y. (2007) Quantum Dots for Multicolor Tumor Pathology and Multispectral Imaging. Methods in Molecular Biology, 374, 29-42.

[10] Gao, X., Chung, L.W. and Nie, S. (2007) Quantum Dots for in Vivo Molecular and Cellular Imaging. Methods in Molecular Biology, 374, 135-145.

[11] Frangioni, J.V., Kim, S.-W., Ohnishi, S., Kim, S. and Bawendi, M.G. (2007) Sentinel Lymph Node Mapping with Type-II Quantum Dots. Methods in Molecular Biology, 374, 147-159.

[12] Manzoor, K., Johny, S., Thomas, D., Setua, S., Menon, D. and Nair, S. (2009) Bio-Conjugated Luminescent Quantum Dots of Doped ZnS: A Cyto-Friendly System for Targeted Cancer Imaging. Nanotechnology, 20, Article ID: 065102. http://dx.doi.org/10.1088/0957-4484/20/6/065102

[13] Ornberg, R.L. and Liu, H. (2007) Immunofluorescent Labeling of Proteins in Cultured Cells with Quantum Dot Secondary Antibody Conjugates. Methods in Molecular Biology, 374, 3-10.

[14] Lidke, D.S., Nagy, P., Jovin, T.M. and Arndt-Jovin, D.J. (2007) Biotin-Ligand Complexes with Streptavidin Quantum Dots for in Vivo Cell Labeling of Membrane Receptors. Methods in Molecular Biology, 374, 69-79.

[15] Jaiswal, J.K. and Simon, S.M. (2007) Optical Monitoring of Single Cells Using Quantum Dots. Methods in Molecular Biology, 374, 93-104.

[16] Deerinck, T.J., Giepmans, B.N., Smarr, B.L., Martone, M.E. and Ellisman, M.E. (2007) Light and Electron Microscopic Localization of Multiple Proteins Using Quantum Dots. Methods in Molecular Biology, 374, 43-53.

[17] Bozuyigues, C., Levi, S., Triller, A. and Dahan, M. (2007) Single Quantum Dot Tracking of Membrane Receptors. Methods in Molecular Biology, 374, 81-91.

[18] Gu, W., Pellegrino, T., Park, W.J., Boudreau, R., Gros, M.A., Aliviasatos, A.P. and Larabell, C.A. (2007) Measuring Cell Motility Using Quantum Dot Probes. Methods in Molecular Biology, 374, 125-131.

[19] Geho, D.H., Killian, J.K., Nandi, A., Pastor, J., Gurnani, P. and Rosenblatt, K.P. (2007) Fluorescence-Based Analysis of Cellular Protein Lysate Arrays Using Quantum Dots. Methods in Molecular Biology, 374, 229-237.

[20] Freeman, R. and Willner, I. (2009) NAD+/NADH-Sensitive Quantum Dots: Applications to Probe NAD+-Dependent Enzymes and to Sense the RDX Explosive. Nano Letters, 9, 322-326. http://dx.doi.org/10.1021/nl8030532 
[21] Goldman, E.R., Uyeda, H.T., Hayhurst, A. and Mattoussi, H. (2007) Luminescent Biocompatible Quantum Dots. Methods in Molecular Biology, 374, 207-227.

[22] Zhang, B.B., Liang, X.F., Hao, L.J., Cheng, J., Gong, X.Q., Liu, X.H., Ma, G.P. and Chang, J. (2009) Quantum Dots/ Particle-Based Immunofluorescence Assay: Synthesis, Characterization and Application. Journal of Photochemistry and Photobiology B: Biology, 94, 45-50. http://dx.doi.org/10.1016/j.jphotobiol.2008.09.008

[23] Vu, T.Q., Maddipati, R., Blute, T.A., Nehilla, B.J., Nusblat, L. and Desai, T.A. (2005) Peptide-Conjugated Quantum Dots Activate Neuronal Receptors and Initiate Downstream Signaling of Neurite Growth. Nano Letters, 5, 603-607. http://dx.doi.org/10.1021/nl047977c

[24] Ornberg, R.L., Harper, T.F. and Liu, H. (2005) Western Blot Analysis with Quantum Dot Fluorescence Technology: A Sensitive and Quantitative Method for Multiplexed Proteomics. Nature Methods, 2, 79-81. http://dx.doi.org/10.1038/nmeth0105-79

[25] Sarkar, A., Robertson, R.B. and Fernandez, J.M. (2004) Simultaneous Atomic Force Microscope and Fluorescence Measurements of Protein Unfolding Using a Calibrated Evanescent Wave. Proceedings of the National Academy of Sciences of the United States of America, 101, 12882-12886. http://dx.doi.org/10.1073/pnas.0403534101

[26] Pinaud, F., King, D., Moore, H.P. and Weiss, S. (2004) Bioactivation and Cell Targeting of Semiconductor CdSe/ ZnSnanocrystals with Phytochelatin-Related Peptides. Journal of the American Chemical Society, 126, 6115-6123. http://dx.doi.org/10.1021/ja031691c

[27] Gokarna, A., Lee, S.K., Hwang, J.S., Cho, Y.H., Lim, Y.T., Chung, B.H. and Lee, M. (2008) Fabrication of CdSe/ZnS Quantum-Dot-Conjugated Protein Microarray and Nanoarrays. Journal of the Korean Physical Society, 3, 3047-3050. http://dx.doi.org/10.3938/jkps.53.3047

[28] Bardelang, D., Zaman, M.B., Moudrakovski, I.L., Pawsey, S., Margeson, J.C., Wang, D.S., Wu, X.H., Ripmeester, J.A., Ratcliffe, C.I. and Yu, K. (2008) Interfacing Supramolecular Gels and Quantum Dots with Ultrasound: Smart Photoluminescent Dipeptide Gels. Advanced Materials, 20, 4517-4520. http://dx.doi.org/10.1002/adma.200801812

[29] Rebilly, J.N., Gardner, P.W., Darling, G.R., Bacsa, J. and Rosseinsky, M.J. (2008) Chiral II-VI Semiconductor Nanostructure Superlattices Based on an Amino Acid Ligand. Inorganic Chemistry, 47, 9390-9399. http://dx.doi.org/10.1021/ic801097w

[30] Sutherland, A.J. (2002) Quantum Dots as Luminescent Probes in Biological Systems. Current Opinion in Solid State \& Materials Science, 6, 365-370. http://dx.doi.org/10.1016/S1359-0286(02)00081-5

[31] Li, Z., Du, Y., Zhang, Z. and Pang, D. (2003) Preparation and Characterization of CdS Quantum Dots Chitosan Biocomposite. Reactive and Functional Polymers, 55, 35-43. http://dx.doi.org/10.1016/S1381-5148(02)00197-9

[32] Sondi, I., Siiman, O. and Matijevic, E. (2004) Synthesis of CdSe Nanoparticles in the Presence of Aminodextran as Stabilizing and Capping Agent. Journal of Colloid and Interface Science, 275, 503-507. http://dx.doi.org/10.1016/j.jcis.2004.02.005

[33] Tan, W.B. and Zhang, Y. (2005) Surface Modification of Gold and Quantum Dot Nanoparticles with Chitosan for Bioapplications. Journal of Biomedical Materials Research Part A, 75, 56-62. http://dx.doi.org/10.1002/jbm.a.30410

[34] Wang, X.H., Du, Y.M., Ding, S., Fan, L.H., Shi, X.W., Wang, Q.Q. and Xiong, G.G. (2005) Large Two-Photon Absorbance of Chitosan-ZnS Quantum Dots Nanocomposite Film. Physica E: Low-Dimensional Systems and Nanostructures, 30, 96-100. http://dx.doi.org/10.1016/j.physe.2005.07.017

[35] Nie, Q., Tan, W.B. and Zhang, Y. (2006) Synthesis and Characterization of Monodisperse Chitosan Nanoparticles with Embedded Quantum Dots. Nanotechnology, 17, 140-144. http://dx.doi.org/10.1088/0957-4484/17/1/022

[36] Sun, X.L., Cui, W., Haller, C. and Chaikof, E.L. (2004) Site-Specific Multivalent Carbohydrate-Labeled Quantum Dots and Magnetic Beads. ChemBioChem, 5, 1593-1596. http://dx.doi.org/10.1002/cbic.200400137

[37] Osaki, F., Kanamori, T., Sando, S., Sera, T. and Aoyama, Y. (2004) A Quantum Dot Conjugated Sugar Ball and Its Cellular Uptake. On the Size Effects of Endocytosis in the Subviral Region. Journal of the American Chemical Society, 126, 6520-6521. http://dx.doi.org/10.1021/ja048792a

[38] Dirar, H.M.E. (2008) Strong Band-Edge Emission from ZnS Quantum Dots Stabilized by Gum Arabic. Chinese Physics Letters, 25, 4480-4481. http://dx.doi.org/10.1088/0256-307X/25/12/083

[39] Cheng, Z.Y., Liu, S.H., Beines, P.W., Ding, N., Jakubowicz, P. and Knoll, W. (2008) Rapid and Highly Efficient Preparation of Water-Soluble Luminescent Quantum Dots via Encapsulation by Thermo- and Redox-Responsive Hydrogels. Chemistry of Materials, 20, 7215-7219. http://dx.doi.org/10.1021/cm800733y

[40] Wang, C.H., Hsu, Y.S. and Peng, C.A. (2008) Quantum Dots Encapsulated with Amphiphilic Alginate as Bioprobe for Fast Screening Anti-Dengue Virus Agents. Biosensors and Bioelectronics, 24, 1012-1019.

http://dx.doi.org/10.1016/j.bios.2008.08.009

[41] Li, H.B. and Han, C.P. (2008) Sonochemical Synthesis of Cyclodextrin-Coated Quantum Dots for Optical Detection of 
Pollutant Phenols in Water. Chemistry of Materials, 20, 6053-6059. http://dx.doi.org/10.1021/cm8009176

[42] Khachatryan, G., Khachatryan, K., Stobinski, L., Tomasik, P., Fiedorowicz, M. and Lin, H.M. (2009) CdS and ZnS Quantum Dots Embedded in Hyaluronic Acid Films. Journal of Alloys and Compounds, 481, 402-406. http://dx.doi.org/10.1016/j.jallcom.2009.03.011

[43] Khachatryan, K., Khachatryan, G., Fiedorowicz, M. and Tomasik, P. (2014) Formation and Properties of Selected Quantum Dots in Maize Amylopectin Matrix. Journal of Alloys and Compounds, 607, 39-43. http://dx.doi.org/10.1016/j.jallcom.2014.04.082

[44] Lii, C.Y., Tomasik, P., Hung, W.L., Yen, M.T. and Lai, V.M.F. (2003) Granular Starches as Dietary Food and Microcapsules. International Journal of Food Science \& Technology, 38, 677-685. http://dx.doi.org/10.1046/j.1365-2621.2003.00685.x

[45] Ciesielski, W. and Tomasik, P. (2004) Metal Complexes of Amylose and Amylopectins and Their Thermolysis. Journal of Inorganic Biochemistry, 98, 2039-2051. http://dx.doi.org/10.1016/j.jinorgbio.2004.09.010 